\title{
Social Internet-networks in the life of Vietnamese students
}

\author{
Tran Dinh Tan $\mathrm{Xu}^{1}$, Natalia S. Polyakova ${ }^{1}$, and Svetlana S. Shipilova ${ }^{1}$ \\ ${ }^{1}$ Tomsk Polytechnic University, 634050 Lenin Avenue, 30, Tomsk, Russia
}

\begin{abstract}
The description of the results of research of influence of virtual social networks on the life of Vietnamese students studying in Tomsk Polytechnic University and in several Universities of Vietnam is represented in this article. The research is aimed at both determination of how Vietnamese students use a social Internet-network and determination of a possibility of using social networks in teaching international students at TPU. Interests and needs of Vietnamese students in social Internet-networks were chosen as the subject of study. The method of online survey in the resource of Google Drive was used for research. The results of this research can be used in the learning process as an additional resource for successful training of Vietnamese students in the Russian-speaking environment.
\end{abstract}

\section{Introduction}

The Internet has become an integral part of the lives of millions of people in modern world. This phenomenon has enveloped big developed countries as well as small developing states. Internet communication is used in all spheres of human activity. In the last decade it has become very popular to use the Internet for communication. Web sites of social networks were set up and are being developed for this aim. There is a specific definition of a social network.

A social network (virtual social network) is a community of users united by a certain online platform (by a website or a service), which main characteristic is the possibility of free interaction between users in order to establish and maintain social networks [1].

It is known that social networks are a relatively new phenomenon: the official starting point of the history of social networks is considered to be the year of 2004 - the year of Facebook starting. Subsequently, such international social networks as MySpace, Twitter and Russian social networks as Vkontakte and Odnoklassniki received the greatest fame and popularity together with Facebook [1].

The rapid development of social networks in the Internet and their popularity growing every year attract the attention of researchers from different countries. Great interest has been shown to the youth audience. The following important questions raise: to what degree young people are obsessed with this phenomenon; how much time they spend for communication and viewing the profiles; what positive factor is in social networks and if there is a negative impact of social networks on the students of different educational institutions? These and other questions are of concern not only to

a Corresponding author: xutranpc@gmail.com researchers, but also to parents of young people and their teachers.

In this article the description of the results of research of influence of virtual social networks on the life of Vietnamese students studying in Tomsk Polytechnic University and several Universities of Vietnam is presented. The authors of the paper used the research materials presented in the analytical report as the results of the research project "The role of virtual social networks in the modern students' life" realized in the Laboratory of monitoring studies of Moscow State Psychological and Pedagogical University in 2013.

The research is aimed both at determination of how Vietnamese students use social Internet-networks and determination of a possibility of using social networks in teaching international students at TPU.

The following tasks were set for achievement of these goals:

1. identification of websites in social networks which are popular among Vietnamese students;

2 . study of the time range and frequency of using social networks by Vietnamese students;

3. determination of practical benefits of social networks for Vietnamese students.

Vietnamese students studying at Russian Universities (at TPU) and at various Universities of Vietnam were chosen as the object of the study. Interests and needs of Vietnamese students in social Internet-networks were chosen as the subject of the study. For the study the group in which one half of the students is studying in Russia and another studying in Vietnam was formed.

The methods of online survey in the resource of Google Drive and data processing by simple statistical methods were used for research. 


\section{Materials and methods}

The case of "virtual world" in Vietnam was considered. Of the 90 million of Vietnamese, 44\% (there are 41 million) use the Internet. Statistics also show the gender equality (50/50 men and women) and the predominance of the rural population $(69 \%)$. It is a good indicator of informatization for Indo-China [7].

The analyst Vincenzo Cosenza conducted the research concerning the popularity of social networks in the world twice and charted a visual map as early as 2012. According to the results of study, the social network of Facebook is not the world most popular in several countries.

There are the countries in which Facebook loses to local social networks:

- Russia (the first place in popularity among Russians is Vkontakte, the second one is Odnoklassniki);

- China (there are some social networks which are more popular than Facebook, they are QZone (560 million of users), Tencent Weibo (337 million) and Sina Weibo (334 million));

- Vietnam and Latvia (their local social networks Zing and Draugiem, respectively, are also more popular);

- Iran (Facebook is not popular by political reasons because of censorship in this country it is almost impossible to visit the site [4]).

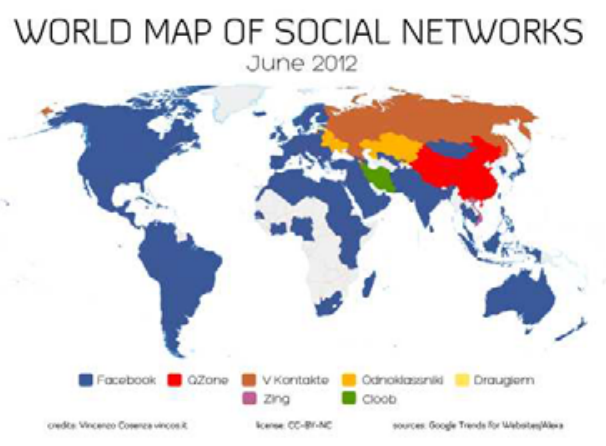

Fig. 1. The map of popularity of various social networks

In 2013 the Government of Vietnam presented their own social network - Zing. And for some period of time it was the most popular in this country.

In 2013 the Vietnamese government adopted the bill about the full Internet censorship, it is Decree 72. Within the law users are not permitted to discuss news items in the social networks and blogs. These platforms can only be used for personal correspondence in the network. The law also provides for the deployment of local servers of all foreign companies operating in Vietnam in the territory of the state. The bill prohibits the publication of material criticizing the Vietnamese government as well as those that are "harmful to national security". The Minister of Information and Communications of Vietnam Le Nam Chang said earlier that this law is intended to reduce the amount of false information in network [6].

In today's Vietnam the information about the popularity of various social platforms is changing at breakneck speed.
Currently, in Vietnam 30 million of users visit the social network "Facebook" according to the latest statistics from this social network. This amount is a third of the total population. Also according to this source, this number is by $13 \%$ more than the average amount of using the social networks worldwide per day. Residents of Vietnam spend about 2,5 hours per day on Facebook, it is more than 1 hour in comparison with other social networks and twice as much than time spent by watching television [5].

\section{Results and discussion}

Thus in Vietnam there is a fairly broad audience of users of social networks.

In this article the questions of influence of social networks on the lives of Vietnamese students studying at Tomsk Polytechnic University and at the Universities of Vietnam are considered.

To achieve the objectives of the study, the questionnaire consisting of 14 questions was composed. Questions were asked in an online mode in the Vietnamese language.

The answers to the first question determined the number of Vietnamese students studying in Russia at Tomsk Polytechnic University and separately the number of students studying in Vietnam. The distribution of respondents by the place of learning was equal (Figure 2).

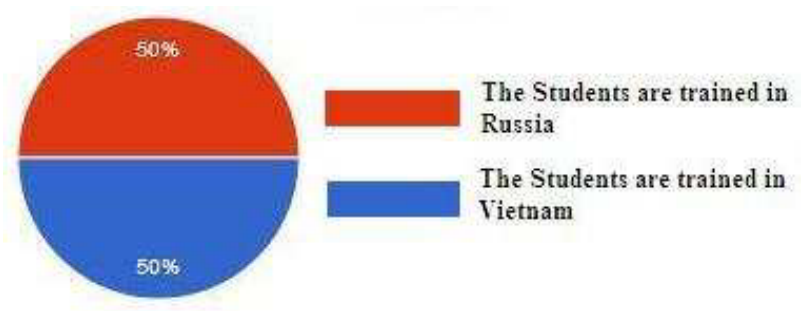

Fig. 2. Distribution of respondents by the place of learning

The distribution of the study by gender is the following: girls are $35 \%$ and boys are $65 \%$ (Figure 3 ).

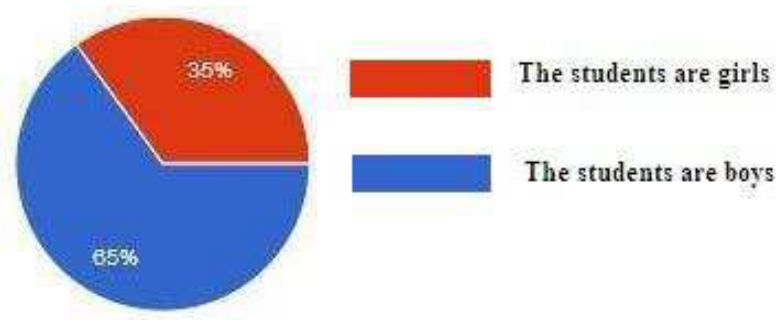

Fig. 3. Distribution of respondents by gender

The survey consisted of several questions [1]. Question 1. Why do you use social networks? The respondents' answers were distributed as follows (Figure 4). The greatest number of respondents believe that it allows finding a way to solve their daily problems 
(91\%) as well as it is easy to be connected with other people and communicate $(72 \%)$.

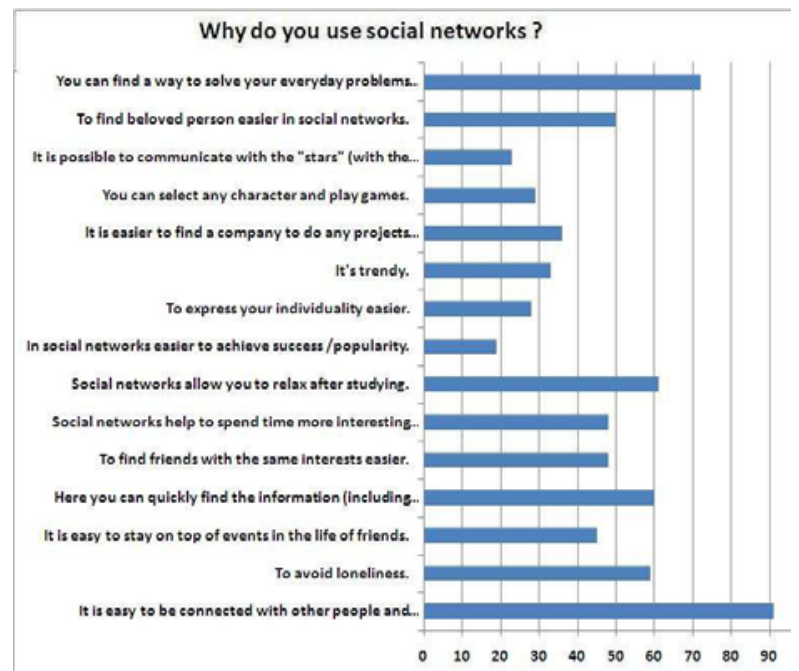

Fig. 4. Distribution of respondents' answers to question 1

The results of answers to question 2 "What social networks do you use?" were very interesting (Table 1).

Table 1. Using a variety of social sites.

\begin{tabular}{|c|c|c|}
\hline Social networks & $\begin{array}{c}\text { The number } \\
\text { of students }\end{array}$ & $\begin{array}{c}\text { The number in } \\
\text { percentages }\end{array}$ \\
\hline Facebook & 100 & $100 \%$ \\
\hline Zing & 51 & $51 \%$ \\
\hline Vkontakte & 35 & $35 \%$ \\
\hline Twiter & 1 & $1 \%$ \\
\hline Instagram & 13 & $13 \%$ \\
\hline Skype & 80 & $80 \%$ \\
\hline Youtube & 88 & $88 \%$ \\
\hline Zalo & 51 & $51 \%$ \\
\hline another & 1 & $1 \%$ \\
\hline
\end{tabular}

All the interviewed students have a profile in Facebook, and a little more than half of them use national social network Zing. But Russian network Vkontakte is popular among $35 \%$ of the the interviewed students. This result can be explained as follows. Vietnamese students who are studying at TPU and know the Russian language have profiles in VKontakte. The most popular networks after Facebook are Skype (80\%) and Youtube (88\%) according to the survey.

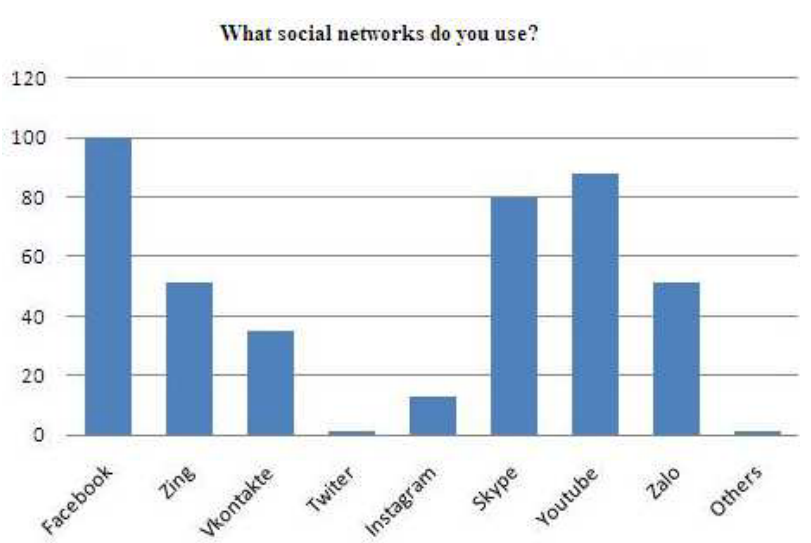

Fig. 5. Distribution of respondents' answers to question 2

Question 3. Which social network is the most important (main) for you? As noted by $84 \%$ of respondents the most important is Facebook.

Which social network is the most important (main) for you ?
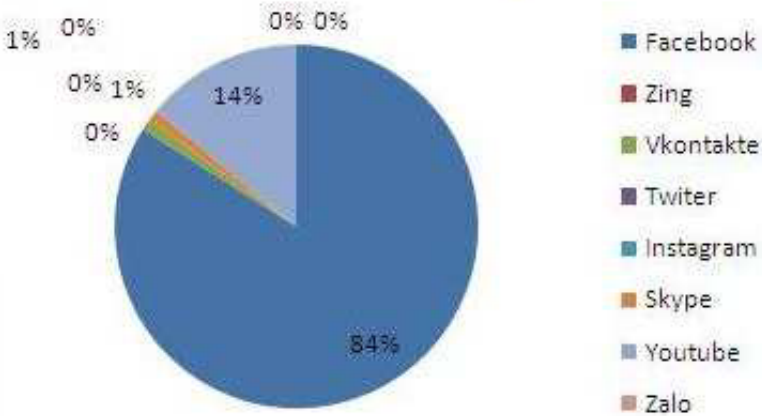

Fig. 6. Distribution of respondents' answers to question 3

Question 4. What attracts you in your main social network most of all? The most important criteria for choosing Facebook are the following:

1. In this social network, it is easier to find the information in which I am interested $(73 \%)$;

2. This network is very easy to use $(72 \%)$;

3 . There are many opportunities in this network $(71 \%)$.

What the most attracts you in your main social network?

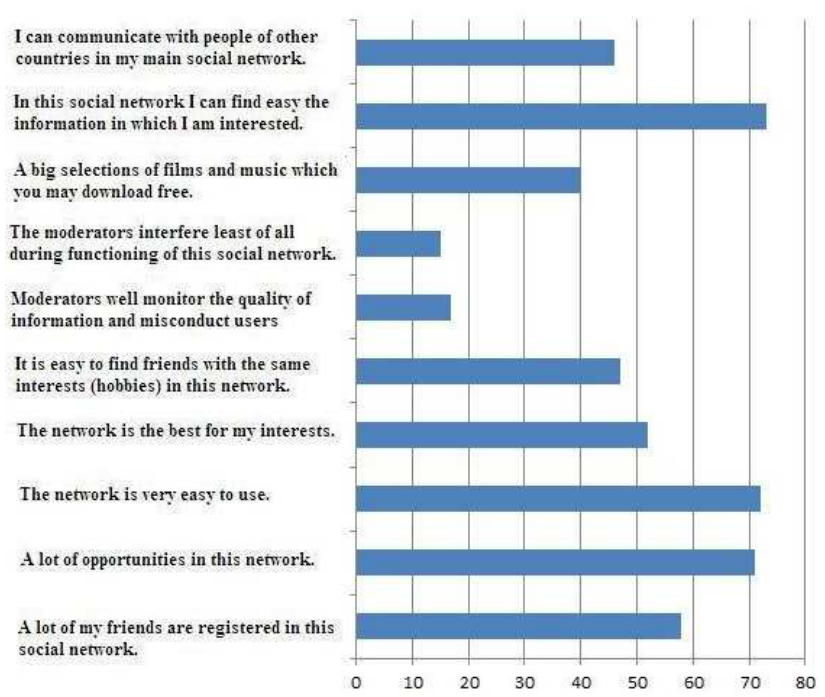

Fig. 7. Distribution of respondents' answers to question 4

Question 5. How many years do you use your main social network? 
How many years do you use your main social network?

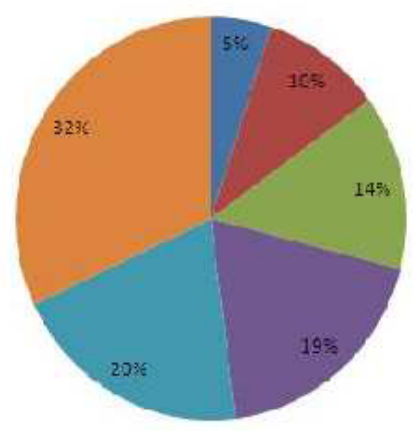

Fig. 8. Distribution of respondents' answers to question 5

Question 6. How often do you enter your personal profile in your main social network?

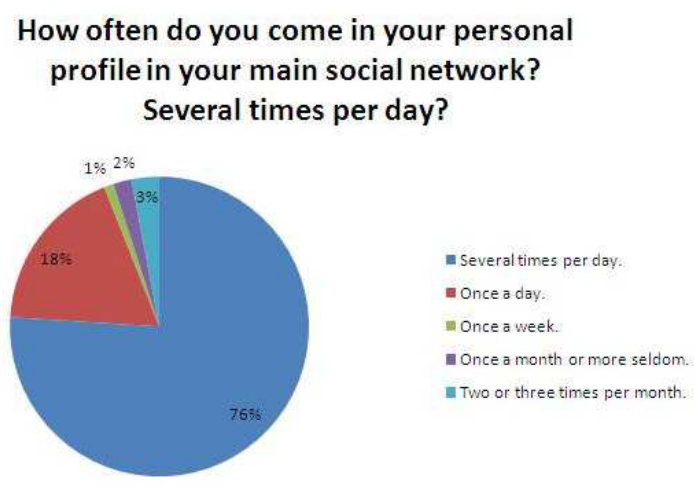

Fig. 9. Distribution of respondents' answers to question 6

Question 7. How much time do you spend in your main social network? The majority of students (42\%) answered that they spend in the social networks from 1 to 3 hours. $33 \%$ of respondents spend less than one hour in the network.

\section{How much time do you spend in your main social network?}

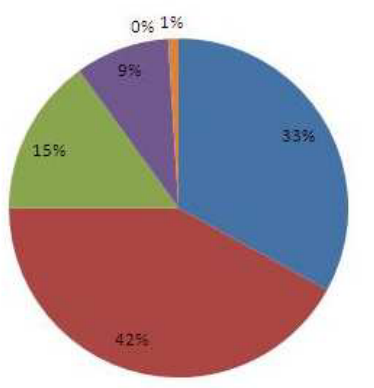

- Less then hour.

$1-3$ hours.

in $3-5$ hours.

- $5-8$ hours.

= 8-12 hours.

More than 12 hours.

Fig. 10. Distribution of respondents' answers to question 7

Question 8. How many friends do you have in your main social networks? The results were incredible: $31 \%$ of respondents have more than 500 friends, $26 \%$ have from 300 to 500 friends, and $8 \%$ have less than 100 friends.
How many friends do you have in your main social netwoks?

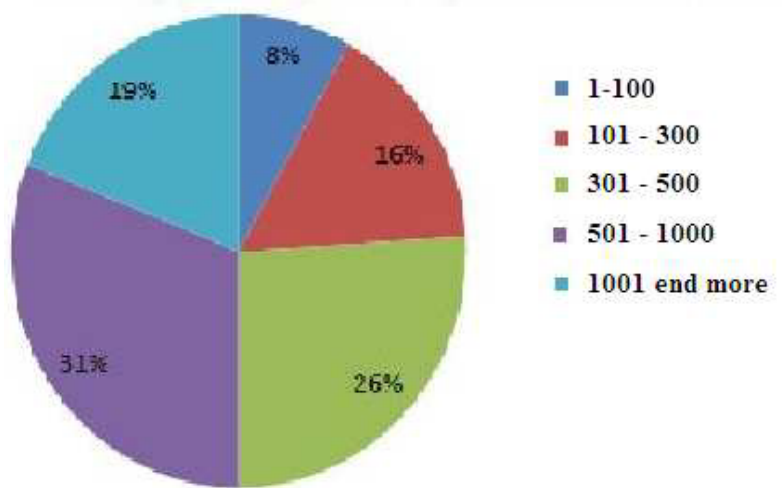

Fig. 11. Distribution of respondents' answers to question 8

Question 9. How many friends do you have in your real life?

\section{How many friends do you have in your real life?}

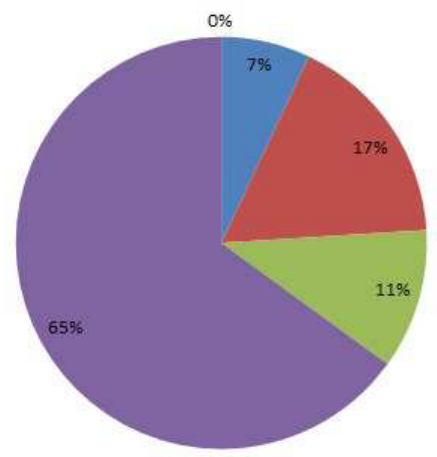

=1-5

$=6-10$

III 11 - 15

More than 15

II I have no friends. I have just acquaintances.

Fig. 12. Distribution of respondents' answers to question 9

Question 10. How many friends from social networks are friends in your real life?

\section{How many friends from social networks are friends in your real life?}

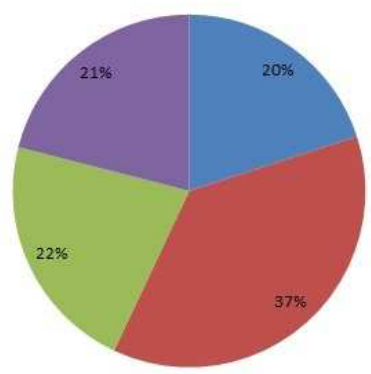

in Absolutely all of them

malmost all but one or two more then half of them. in Less then half of them

Fig. 13. Distribution of respondents' answers to question 10

Question 11. Are your parents the users of social networks? 


\section{Are your parents the users of social networks?}

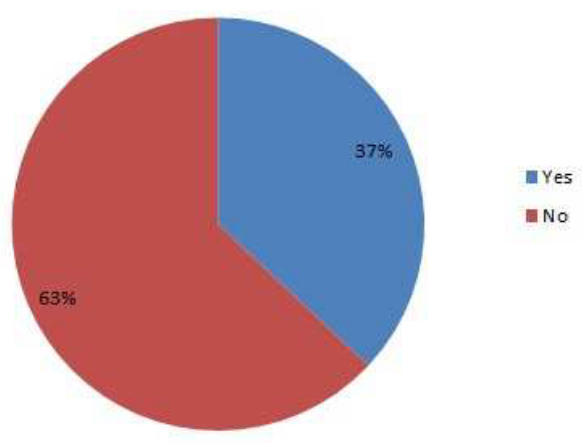

Fig. 14. Distribution of respondents' answers to question 11

Question 12. Do your parents belong to "your friends" group in social networks?

\section{Are your parents your friends in social networks?}

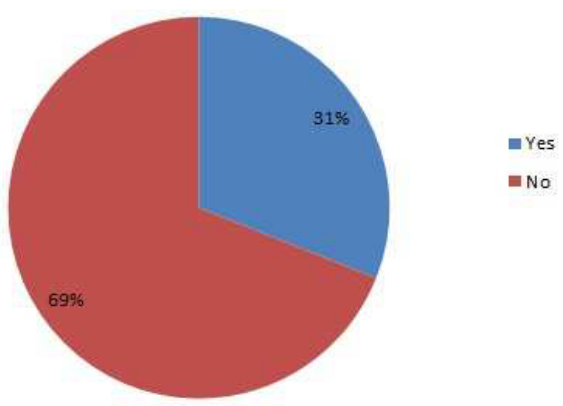

Fig. 15. Distribution of respondents' answers to question 12

Question 13. What is the influence of the use of social networks on studying?

What is the influence on studying of using of social networks?

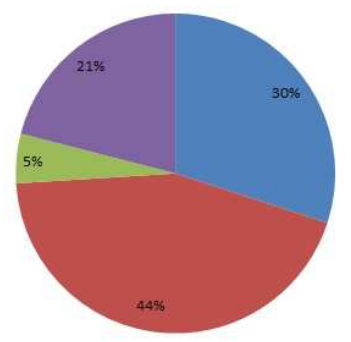

Social networks helpalot. - Social networks help few. nsocial networks don't help. - Social networks interfere.

Fig. 16. Distribution of respondents' answers to question 13

\section{Conclusion}

This research showed that social networks are important to Vietnamese students. Virtual communication on different platforms is quite common. The vast majority of the interviewed students believe that virtual social networks are an extremely affordable and convenient way to communicate. Besides, they are an indispensable aid in the solution of everyday problems, including students' study. The most popular social network is Facebook.

A large number of respondents use social networks several times a day. Many students spend from one to three hours a day using social networks. Each of the interviewed students has a large number of friends in the networks, many of whom are friends in real life. Vietnamese students studying in Russia for a few years do not visit Vietnam during this period, so virtual communication with parents is especially important. The results of the survey showed that students solve this problem through social networks: in networks, friends are the parents for the majority of respondents. Vietnamese students admit that the use of social networks helps them in their studies.

Based on the results mentioned above, the authors concluded that the use of social networks during communication between the teacher and students can give good results in training.

\section{Acknowledgment}

The programme was realized and subsided within the framework of the Programme for enhancing Tomsk Polytechnic University's competitiveness. The results presented herein were obtained with the assistance of Russian Fond.

\section{References}

1. E.V. Arzhanykh, I.V. Zadorin, E.Yu. Kolesnikova, O.A. Gurkina, E.M. Novikova, D.V. Maltseva, The report on the results of scientific and research work, 107, (2014)

2. International Research Journal of Interdisciplinary \& Multidisciplinary Studies, I, 8 (2015)

3. The Effect of Social Networking Sites on Students' Academic Performance in Girne American University, http://ydemokrat.blogspot.com/2013/05/the-effectof-social-networking-sites.html

4. The Largest social network and other social networks: regional differences, $\underline{\mathrm{http}}$ //internetua.com/krupneishaya-socset-i-drugiesocseti--razlicsiya-po-regionam

5. Tình hình, Sưdụng Facebook ởViệt Nam, (2014), http://www.asiaplus.net/pr/Facebook_PR_1119 VN.pdf

6. The law about Internet censorship came into force In Vietnam, (2013), http://www.securitylab.ru/news/444020.php

7. http://iwpro.ru/vietnam.html 